\section{Cancer as deviant differentiation}

\author{
D.G. Harnden
}

Cancer Biology. By Raymond W. Ruddon. Pp.344. Hbk ISBN 0-19-502942-9; pbk ISBN 0-19-502943-7. (Oxford University Press: 1982.) Hbk \$21.95; pbk \$14.95, £10.

IT is relatively easy to describe the characteristics of cancer cells but rather more difficult to say which ones are critical for conferring malignancy. Similarly, it is easy to conclude that there must be an alteration in the genome; but whether the change is structural, regulatory or a combination of the two has always seemed rather harder to define. It comes as something of a culture shock, therefore, to find a book which not only assumes that it is the regulatory changes that are fundamental but makes this thesis sound uncomfortably convincing for an advocate of somatic mutation. To quote Dr Ruddon (p.55):

What we need to know to understand carcinogenesis and to develop ways of preventing or curing cancer, then, is contained in the mechanisms of normal cellular differentiation.

It has been clear for some time that an understanding of differentiation could prove to be very important in some cancers, but we now have to reckon with the

\section{YOU CAN AFFECT NUCLEAR STANDARDS}

$6,000+$ standards used in construction of a nuclear unit

$600+$ standards to which on line operating units must conform

$\$ 2 \frac{1}{4}$ billion a year maintenance, operations and refueling market for 72 U.S. operating units

These numbers affect you. You can affect them by joining the American Nuclear Society's ICONS service

INFORMATION CENTER ON NUCLEAR STANDARDS

\section{ICONS OFFERS}

- Nuclear Standards News, the only monthly standards newsletter

- All ANS approved standards upon publication

- Opportunity to review and comment on developing ANS standards

- Abstracts of US and international standards

- Plus research time, Nuclear News magazine, Washington Nuclear Report and more

Write today for information and your free list of current standards

Tel. $312 / 352-6611$-TELEX: 254635

American Nuclear Society 555 No. Kensington Avenue La Grange Park, IL 60525 USA possibility that, for the majority of cancers, the principal irregularity is a deviation from, or an arrest at some point in, the pathway of development of the stem cell into a mature differentiated cell. The association between mutagenesis and carcinogenesis, however, is too strong to be unimportant; but it may be that the link lies in the structure and function of regulatory sequences, whose potential for controlling the balance between preparation for cellular proliferation and the production of specific products of the differentiated cell we are only just beginning to understand.

Dr Ruddon does not go out of his way to advocate the importance of regulatory phenomena. Indeed in later chapters he deals quite fully and fairly with the role of mutational events. Some might call the overall presentation unbalanced, but I found it an interesting and stimulating approach in which the author's personal views and areas of interest feature quite prominently. This makes it much more compelling to read than a multi-author book and makes the breadth of coverage quite remarkable. Little prior knowledge of cancer nor indeed of complex biological techniques is assumed, and this makes it a very good book for senior students and those entering research projects in this field - as well as refreshing for those more fixed in their ways.

D. G. Harnden is Professor of Cancer Studies at the University of Birmingham, England.

\title{
Ecological theory meets mycological data
}

\section{C.T. Ingold}

The Fungal Community: Its Organization and Role in the Ecosystem. Edited by Donald T. Wicklow and George C. Carroll. Pp.855. ISBN 0-8247-6956-2. (Dekker: 1981.) SwFr. 280, \$98.50.

IN RECENT years mycologists have become increasingly interested in the life processes of fungi in their natural environments, and, at the same time, there has been a growing awareness amongst ecologists of the importance of fungi in the major ecosystems. The mycologist has tended to focus attention on specific niches in which fungi are the dominant organisms; in particular much attention has been given to fungi in the soil. However, the outstanding need is for valid quantitative estimates of the contributions of fungi to the dynamic equilibrium of such major plant communities as forest, prairie or heath. The ecologist is concerned with all of the components of these communities and how they interact. By their very nature, the fungi are perhaps the most difficult to handle.

The Fungal Community, as Swift says in his foreword, is an evangelistic work. It has the worthy aim of stimulating mycologists and ecologists to concerted and integrated endeavour. No less than 52 authors, including some general ecologists, have contributed 41 chapters which are divided into eight parts: fungal ecology and ecological theory; fungal populations; organization of fungal communities; interactions among fungal populations; fungal community development; fungal productivity in ecosystems; fungi in nutrient re-cycling; and finally the aquatic hyphomycete community as an example of how mycologists have approached a specific ecological problem.
The individual chapters are of diverse nature and quality. Some are excellent such as Wicklow on the coprophilous community; Emerson and Natvig on adaptation of fungi to stagnant waters; Frankland on fungal succession; Starmer on yeasts associated with cacti and spread by species of Drosophila; Lindeberg on nitrogen cycling in coniferous forests; and Suberkropp and Klug on degregation of leaves by aquatic hyphomycetes. However, a number of chapters are mediocre. In all, one is left with the feeling that if, instead of 52 authors, a quarter of that number under closer editorial control had contributed, a more valuable and influential work might have resulted.

Three chapters deal with lichens, but the value of considering them in this book is doubtful. As Pike, in his chapter on lichen biomass, remarks "the thallus of lichens bears more similarity to the body of a green plant than it does to the mycelium of most fungi".

Nonetheless, The Fungal Community will be read with interest not only by mainstream ecologists concerned with the whole ecosystem, but also by the growing number of mycologists who are taking an ecological approach that is at the same time both experimental and quantitative. (Incidentally it is to be hoped that, in adopting and adapting ecological methods, these mycologists will be at pains to avoid indulging in too much ecological jargon.) The path ahead in the study of the ecology of fungi will undoubtedly be beset with difficulty, but the production of this book is one step forward.

C.T. Ingold is an Emeritus Professor of the University of London, and a former President of the British Mycological Society. 